Table 2

Statistical Differences in Step-Through Latencies Benteen Days 1. 2, and 10

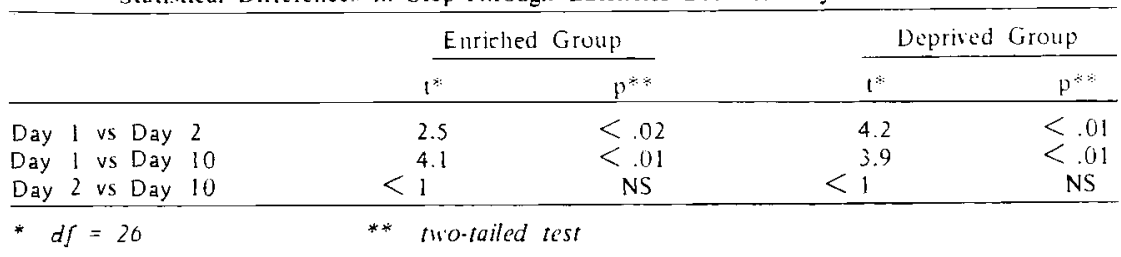

study (Hymovitch, 1952; Bingham \& Griffiths, 1952: Krech et al, 1962: Forgays \& Read, 1962). Furthermore, using the sume environmental stimulation apparatus, an identical group of Ss, and.a very similar procedure, Kirkby \& Kirkby (1968) found significant differences between enriched and deprived groups in spontaneous alternation, a phenomenon associated with learning ability (Parkes. 1965; Lester. 1967: Kirkby, 1967). Thus, it seems probable that the environmental treatment did result in differences in learning ability.

It is possible that the deprived rats. being more emotional, tended to "freeze" on the perch outside the step-through hole, so lengthening step-through latencies. However, the finding that the deprived rats vacated the perch as rapidly as the enriched rats on Day 1 indicated that this explanation was unlikely. A similar lack of differences between enriched and deprived rats in failures to leave a startbox was reported by Kirkby \& Kirkby (1969).

This leaves the third possibility, that the step-through problem was too simple a technique to detect differences in learning ability resulting from environmental treatment in rats.

In the light of the findings of Hymovitch (1952), Bingham \& Griffiths (1952), Krech et al (1962), Forgays \& Read (1962), and Kirkby \& Kirkby (1968), this explanation appears the most feasible interpretation of the present results.

\section{REFFRENCFS}

BINGHAM. W. E. \& GRII IITHS, W. J. The effects of different environments during infancy on adult behavior in the rat. Joumal of Comparative \& Physiological Psychology. 1952.45.307.312.

DF NENBERG. V. H.. \& MORTON. J. R. Effects of environmental complexity and social groupings upon modification of emotional bchavior. Journal of Comparative \& Physiological Puychology, 1962. 55, 242-246.

ISSMAN, W. B.. \& ALPERN. H. P. Single-trial conditioning methodology, and results with mice, Psychological Reports. 1964. 14. $731-740$.

IORGAYS, D. G.. \& READ. J. M. Crucial period for foremsirommentul experisnes in the rat. Journal of Comparative \& Physiological Psychology, 1962, 55, 816-818.

HFBB. D. O. The effects of early experience on problem solving at maturity. American Psychologist, 1947. 2. 306-307.

HOIFMAN. C. S. Fffect of early environmental restriction on subsequent behavior in the rat. Psychological Record. 1959.9.171-177.
HYMOVITCH. B. The effects of experimental variations on problem solving in the rat. Journal of Comparative \& Physiological Psychology. 1952.45. 313-321. Response perseveration interpretation of passive avoidance deficits in hippocampectomized rats. Journal of Comparative \& Physiolocial Psychology, 1966 , 61. 141-143.

KIRKBY, R. J. A maturation factor in spontaneous alternation. Nature. 1967, 215. 784.

KIRKBY, R. J., \& KIRKBY. J. E. Note: Early
KIMBLE. D. P., KIRKBY. R. J.. \& STEIN. D. G.
DONOVAN E. FLEMING and LELAND E. RHODES, V.A. Hospital, Phoenix, Ariz. 85012

Rats were required to make a choice based on brightness cues prior to coming in contact with either a smooth or rough tactual cue. Such a procedure was used in order to determine whether the postchoice presentation of a stimulus other than that eliciting the choice operates as a discriminative cue or whether it acquires reinforcing properties. All animals running to a rough positive cue as opposed to those running to a smooth positive cue were reliably facilitated in rate of acquisition of the task. The tactual distinctiveness of the negative door was of irrelevant cue value. The observed postchoice facilitation was interpreted to indicate that stimulation from the rough tactual cue acquired reinforcing propertics.

In a preliminary investigation. Fleming \& Rhodes (1969) utilized the successive presentation of distinctive brightness and tactual cues in a discrmination paradigm. It was necessary for a rat to make a choice on environmental experience and spontaneous alternation. Psychological Reports, 1968, 23, 1278.

KRECH, D., ROSENZWEIG, M. R., \& BENNETT. E. L. Relations between brain chemistry and problem solving among rats raised in enriched and impoverished environments. Journal of Comparative \& Physiological Psychology, 1962, 55, 801-807.

LESTER, D. Spontaneous alternation and learning in rats. Psychonomic Science, 1967, 9, 575-576.

LLCHINS, A. S., \& FORGLS, R. H. The effect of differential post-weaning environment on the rigidity of an animal's behavior. Joumal of Genetic Psychology, 1955, 86, 51-58.

PARKES, M. W. An examination of central actions characteristic of scopolamine: Comparison of central and peripheral activity in scopolamine, atropine and some synthetic basic esters. Psychopharmacologia, 1965, 7, 1-19.

\section{NOTE}

1. This investigation was supported by funds from the N.S.W. Department of Health.

\title{
Facilitation of brightness discrimination with postchoice tactual stimulation
}

the basis of visually mediated (black-white) cues prior to coming in contact with either a smooth or rough tactual cue. It was observed that rough tactual stimuli, when associated with the positive brightness cue, reliably facilitated the acquisition of the brightness discrimination with both intact and neodecorticated Ss. On the other hand, the association of distinctive tactual stimuli with the negative brightness cue had questionable effects on task acquisition. Under some conditions, the rough negative cue appeared either to hinder or to facilitate the acquisition of the brightness discrimination. For the most part, however, the tactual component of the negative brightness cue appeared to be irrelevant to the task. The data favored the interpretation that, rather than operating as a discriminative cue, the rough tactual cue apparently acquired reinforcing properties. To explore the feasibility of this interpretation, the investigation was replicated and extended. Special attention was directed to the role of the tactual component of the negative brightness cue. SUBJECTS

Forty-eight adult male albino rats of the 
Holtzman strain, 90-120 days of age at the start of the investigation, were used.

\section{APPARATUS}

The training procedures were carried out in a standard discrimination chamber. Two exit doors, separated by a divider, were mounted at one end of the chamber. The divider created two 4-in. alleys leading to the doors. Three separately controlled grids formed the floor of the chamber, one each in the alleys in front of the doors, the third forming the floor for the remainder of the chamber. This remaining area served as the starting chamber. The doors that allowed entrance into an escape chamber could be independently locked in the closed position. Distinctive stimulus cards could be easily affixed to and removed from the doors. Number $2 / 0$ garnet (smooth) sandpaper pieces were glued to two stimulus cards and No. 2 garnet (rough) sandpaper pieces were glued to the remaining two cards. One of each type of sandpaper-faced card was painted flat black, one of each painted flat white. When in place in the doors and illuminated from in front and slightly above by a $60-\mathrm{W}$ incandescent lamp, the photometric brightness of the white stimulus cards was approximately $19 \mathrm{~mL}$, the black stimulus cards approximately $2 \mathrm{~mL}$. When tested at the conclusion of the investigation, control and operated animals could not distinguish visually between smooth-white and rough-white doors. The surfaces of the ,training box were painted gray.

\section{PROCEDURE}

Prior to actual experimentation, 3 days of training were provided in the apparatus wherein each animal learned to move directly through either of the two exit doors to avoid a foot shock. During this phase of training the doors were gray. Following door training, the experiment proper was carried out. The positive brightness cue was a white door, the negative cue a black door. One-half of the Ss ran to a smooth-white (SW) positive cue, one-half to a rough-white (RW) positive cue. Similarly, half of the Ss were tested with a smooth-black (SB) negative cue and half to a rough-black (RB) negative cue. The cue combinations were counterbalanced in the following manner: SW-SB (positive door-negative door), SW-RB, RW-SB, RW-SB.

Twenty-five trials per day were run until an animal reached the criterion level of $90 \%$ correct choices ( 18 correct choices in a block of 20 trials). A corrective procedure was used, an error being scored when an animal ran into the negative alley and was shocked. A $S$ needed only to put its front feet into the negative alley to receive a $0.45-\mathrm{mA}$ shock. In order to receive tactual stimulation from the stimulus card, the animal of course must touch the card affixed to the door. The position of the positive cue was determined with the use of a modified Gellermann series (Hilgard, 1961). An intertrial interval of $30 \mathrm{sec}$ minimum was used. The maximum in terval generally did not exceed $120 \mathrm{sec}$.

The trials to criterion were examined in two dimensions with andysis of variance techniques: (1) smooth-rough components of the white cue and (2) smooth-rough components of the black cue.

\section{RESULTS}

As it was necessary for $S$ to cross an electrified grid to reach the negative door, the alley was traversed to the door infrequently and generally only during the early phases of training. To assess the relevance of the negative door tactual cue, an analysis of the trials to criterion for each treatment group was carried out. Such an analysis indicated that the texture of the negative stimulus card was an irrelevant cue for all treatment groups $(\mathrm{F}=2.09$, $\mathrm{df}=1 / 44, \mathrm{p}>.10)$. On the other hand, with respect to the positive door tactual cue, the rates of acquisition of rats running to rough cues were significantly greater than the rates of those animals running to smooth cues $(F=20.11, \quad d f=1 / 44$, $\mathrm{p}<.001)$. These results are summarized in Table 1. The two-dimensional interaction was not significant.

\section{DISCUSSION}

Because of the experimental conditions employed in this investigation, it was necessary for a $S$ to select one of two alleys in order to enter an escape chamber. However, the postchoice entry into one or the other of the two alleys had quite different consequences. Entrance in to the negative alley was associated with immediate noxious electrical stimulation. Upon entering the negative alley and being shocked, an animal would rapidly withdraw without coming in contact with the tactually distinct surface of the locked escape door. This being the case, the tactual component of the negative stimulus card proved to be an irrelevant cue for each treatment group. On the other hand,

Table 1

Mean Trials to Criterion for Brightness and Tactual Cue Combinations

\begin{tabular}{|c|c|c|c|}
\hline & \multicolumn{3}{|c|}{$\begin{array}{l}\text { Tactual-Brightness } \\
\text { Cue Contingencies }\end{array}$} \\
\hline & $\begin{array}{l}\text { Smooth- } \\
\text { White }\end{array}$ & $\begin{array}{l}\text { Rough- } \\
\text { White }\end{array}$ & $\begin{array}{l}\text { Means } \\
\text { Combined }\end{array}$ \\
\hline Smooth-Black & 83.9 & 71.3 & 77.6 \\
\hline Rough-Black & 101.0 & 68.7 & 84.8 \\
\hline $\begin{array}{l}\text { Means } \\
\text { Combined }\end{array}$ & 92.5 & 70.0 & \\
\hline
\end{tabular}

entrance into the positive alley was associated with an absence of shock and unimpaired movement into the escape chamber. These reinforcing conditions were common to all animals ontering this alley. In addition, the tactual distinctiveness of the positive escape door proved to be of marked cue value. Analysis of the differences in rate of task acquisition in the smooth-rough treatment dimension indicated that animals rumning to a rough-surfaced positive door acquired the task at a reliably faster rate than did animals running to a smooth-surfaced door.

A question remains concerning the manner of operation of the rough cuc, i.e.. did the rough stimulus provide discriminative cues or did it acquire reinforcing properties? With a corrective procedure, as used in this investigation. either a positive or a negative choice of alley would eventuate in an animal's passing through the positive alley. The tactual stimulation received when passing through the escape door essentially would be postchoice stimulation. Thus, this stimulation would not operate in the general sense of providing discriminative sensory information. Rather, the postchoice tactual stimulation would acquire incentive reinforcing properties. which presumably would be associated with the other reinforcing elements present in the positive alley (Bindra, 1969: Spence. 1956). In this manner, the rough cue would add distinctiveness to the reinforcement provided by passing in to the escape chamber. This distinctiveness would be proportionately greater than that added by stimulation from contact with the smooth-surfaced door.

\section{REFERENCES}

BINDR A, D. Neuropsychological interpretation of the effects of drive and incentive-motivation on general activity and instrumental behavior. Psychological Review, 1969, 75, 1-22.

CHILD, I., \& WENDT. G. R. The temporal course of the influence of visual stimulation upon the auditory threshold. Journal of Experimental Psychology, 1938, 23, 109-127.

COOPER, L. M. Operant behavior as a function of stimulus complexity. Journal of Comparative \& Physiological Psychology. $1963,56,857-862$.

DENNIS, R. \& PORTER, JR.. J. M. Isolated action of compound stimuli in a locomotor habit of rats. Joumal of Genctic Psychology, 1932, 41, 127-135.

FLEMING, D. E., \& RHODES. L. F. Brightness discrimination: Effects of combined tactual and brightness cues with neodecorticated rats. Proceedings of 77 th Annual Convention of American Psychological Association. 1969 , 19S-196.

HILGARD. E. R. Methods and procedures in the study of learning. In S. S. Stevens (Ed.). Handbook of experimental psichology. New York: Wiley. 1951.

SPENCE. K. W. Behatior thoory and conditioning. New Halven London: Yale U'niversity Press, 1964 